\title{
COMMENTARIES
}

\section{Should We Screen for Depression in the Emergency Department?}

Mental illness is a significant and often underappreciated fact of life for emergency department (ED) patients. In this issue of Academic Emergency Medicine, we learn that patients with psychiatric-related diagnoses represent a substantial and growing number of ED visits. Hazlett et al. demonstrated significant increases $(15 \%)$ in ED psychiatric-related diagnoses between 1992 and 2000. ${ }^{1}$ Persons in groups often characterized as lacking access to medical care were most at risk. The ED psychiatric-related diagnoses rate among Medicaid recipients was eight times greater than those with private insurance. The actual number of ED psychiatric-related diagnoses was likely to have been underestimated, because, as the authors note, the study relied only on the top three psychiatric diagnoses and because emergency physicians often miss the diagnosis of mental health illness. ${ }^{2}$

In the second study, Colman et al. demonstrated that individuals who present with self-injury are significantly more likely than controls to return to the ED for a variety of complaints, including mental illness. ${ }^{3}$ This finding complements studies that have shown individuals commonly use health care in the month prior to the self-harming event. ${ }^{4-7}$

These findings suggest the ED is an important location for identification of mental illness and referral for treatment. This is important because of the great number of patients affected, and because many of these patients may lack access to other health services. There may be no other opportunity for diagnosis, and thus treatment, if we fail to diagnose mental illness in the ED.

There are potential consequences for the patient and the physician when there is failure in detecting mental illness. The consequences for the patient include decreased quality of life, and possibly death. The rate of suicide is at least eight times higher in people with depression than that of the general population. ${ }^{8}$ Consequences for physicians are not quite so severe, but nevertheless affect practice (e.g., crowding) and professional satisfaction. Some have suggested that one solution for improving mental health care is screening for mental illness, particularly screening for depression. ${ }^{9-12}$ Depression screening, with subsequent treatment in a general care setting, appears to be effective in reducing further depression in adults. ${ }^{13}$ Moreover, those studies that link screening to treatment showed the best results. ${ }^{14}$

The Society for Academic Emergency Medicine's Public Health and Education Task Force performed a series of systematic reviews to assess the appropriateness of performing selected preventive interventions in the ED. ${ }^{15}$ The review for depression screening was conducted by the authors and Kenneth C. Parsons, $\mathrm{MD}, \mathrm{MPH}$.

There were many articles that studied screening for depression, but only four reports were conducted in the ED. Three were generated from a single research effort that used standardized questionnaires to screen for depression in older asymptomatic ED patients. ${ }^{16-18} \mathrm{~A}$ fourth evaluated a three-question screening instrument to detect depression in elder ED patients by emergency physicians. ${ }^{19}$ None of these studies looked at patientoriented outcomes such as of quality of life or suicide.

Meldon et al.'s findings showed that an impressive prevalence, about $30 \%$, of older patients who presented to the ED may be depressed. They reported that the inability of emergency physicians to recognize depression was significant. ${ }^{16,17}$ Fabacher et al.'s study showed that screening is not difficult and a threequestion screening instrument is a valid screening tool to detect depression in elders. ${ }^{19}$

We conclude, at this time, the evidence is not sufficient to recommend for or against offering this preventive service routinely in the ED. However, the increasing incidence in ED populations, the burden of suffering, and successful screening in other settings suggest more work is needed to truly evaluate the effect of this promising intervention in the ED.

The studies in this month's AEM clearly demonstrate that the incidence of mental illness is rapidly rising and further taxing our already very busy EDs. These rising numbers are likely to be underestimated due to the lack of recognition of mental illness by emergency physicians. The magnitude and implications of these rising numbers, as well as the importance of recognition, cannot be overstated. These articles reinforce the conclusion of our review, that more research must be conducted on ED-based interventions to reduce the burden of suffering from mental illness that may go undiagnosed if not recognized in the ED.-Terry Kowalenko, MD (terryk@med.umich.edu), and Rahul K. Khare, MD, Department of Emergency Medicine, University of Michigan Health System, Ann Arbor, MI doi:10.1197/j.aem.2003.10.015

\section{References}

1. Hazlett SB, McCarthy ML, Londner MS, Onyike CU. Epidemiology of adult psychiatric visits to U.S. emergency departments. Acad Emerg Med. 2004; 11:193-5. 
2. D'Onofrio G, Bernstein E, Bernstein J, et al. Patients with alcohol problems in the emergency department, part 1: improving detection. SAEM Substance Abuse Task Force. Acad Emerg Med. 1998; 5:1200-9.

3. Colman I, Dryden DM, Thompson AH, et al. Utilization of the emergency department after self-inflicted injury. Acad Emerg Med. 2004; 11:136-42.

4. Suminen $\mathrm{KH}$, Isometsa ET, Ostamo AI, Lonnqvist JK. Health care contacts before and after attempted suicide. Soc Psychiatry Psychiatr Epidemiol. 2002; 37(2): 89-94.

5. Gorman D, Masterton G. General practice consultation patterns before and after intentional overdose: a matched control study. Br J Gen Pract. 1990; 40:102-5.

6. Stenager EN, Jensen K. Attempted suicide and contact with the primary health authorities. Acta Psychiatr Scand. 1994; 90:109-13.

7. Michel K, Runeson B, Valach L, Wasserman D. Contacts of suicide attempters with GPs prior to the event: a comparison between Stockholm and Bern. Acta Psychiatr Scand. 1997; 95:94-9.

8. Monk M. Epidemiology of suicide. Epidemiol Rev. 1997; 9:51-68.

9. Attkisson CC, Zich JM (eds). Depression in Primary Care: Screening and Detection. New York: Routledge, 1990.

10. Moore JT, Lilimperi DR, Bobula JA. Recognition of depression by family medicine residents: the impact of screening. J Fam Pract. 1978; 7:509-13.

11. Linn LS, Yager J. The effect of screening, sensitization, and feedback on notation of depression. J Med Educ. 1980; 55:942-9.
12. Zung WWK, Magill M, Moore JT, George DT. Recognition and treatment of depression in a family medicine practice. J Clin Psychiatry. 1983; 44:3-6.

13. Magruder-Habib K, Zung WWK, Feussner JR. Improving physicians' recognition and treatment of depression in general medical care: results from a randomized clinical trial. Med Care. 1990; 28:239-50.

14. Pigmome MP, Gaynes BN, Rushton JL, et al. Screening for depression in adults: a summary of the evidence for the U.S. Preventative Services Task Force. Ann Intern Med. 2002; 136:765-76.

15. Babcock Irvin C, Wyer PC, Gerson LW. Preventive care in the emergency department, Part II: clinical preventive services an emergency medicine evidence-based review. Society for Academic Medicine Public Health and Education Task Force Preventive Services Work Group. Acad Emerg Med. 2000; 7:1042-54.

16. Meldon SW, Emerman CL, Schubert DSP, Moffa DA, Etheart RG. Depression in geriatric ED patients: prevalence and recognition. Ann Emerg Med. 1997; 30:141-5.

17. Meldon SW, Emerman CL, Schubert DSP. Recognition of depression in geriatric ED patients by emergency physicians. Ann Emerg Med. 1997; 30:442-7.

18. Meldon SW, Emerman CL, Moffa DA, Schubert DS. Utility of clinical characteristics in identifying depression in geriatric ED patients. Am J Emerg Med. 1999; 17:522-5.

19. Fabacher DA, Raccio-Robak N, McErlean MA, Milano PM, Verdile VP. Validation of a brief screening tool to detect depression in elderly ED patients. Am J Emerg Med. 2002; 20:99-102. 